\title{
ESTRATÉGIA DE FIDELIZAÇÃO COMO PRÁTICA EMPRESARIAL PARA CONQUISTA DE CLIENTES
}

\section{LOYALTY STRATEGY AS BUSINESS PRACTICES FOR CONQUERING CUSTOMERS}

\author{
ESTRATEGIA DE FIDELIZACIÓN COMO PRÁCTICAS EMPRESARIALES PARA GANAR \\ CLIENTES
}

Cláudio Luiz Chiusoli ${ }^{1}$, Dyesli Rita de Oliveira de Souza², Elis Regina Cardoso Lecenko³, Isabela Wolski Camargo 4

Submetido em: 10/04/2021

Aprovado em: 30/04/2021

e24189

\section{RESUMO}

Em tempos atuais adotar programas de fidelização mediante marketing de relacionamento tornouse uma estratégia importante para as organizações. O objetivo do artigo é analisar as estratégias empresariais quanto à importância e o uso de programas de fidelização de clientes. Desse modo, foram utilizadas fontes de natureza bibliográfica, tais como livros e artigos científicos. Como método de pesquisa foram realizadas coletas junto aos gestores de cidades do interior do Paraná por meio da aplicação de 107 questionários, enviados via Google Forms. Entre as variáveis analisadas, os principais achados apontam que $91,2 \%$ concordam que a empresa procura ter um bom relacionamento com seus clientes, fato que corrobora que apenas $9,8 \%$ consideram que a empresa perdeu clientes que antes eram fiéis. Cerca de 78,4\% afirmam que a empresa tem consciência da importância da fidelização de clientes, apesar de apenas $65,7 \%$ alegarem que possuem estratégias de fidelização; o uso das redes sociais é feito por $64,7 \%$ dos gestores para conquistar novos clientes, fato importante devido ao crescimento constante de tecnologias de comunicação. Por outro lado, 59,8\% concordam que a empresa possui programas de fidelidade e relacionamento; e 40,2\% concordam que a empresa possui controle efetivo de quais são os clientes fiéis. Já com indicadores de menor concordância, somente 33,3\% citam que a empresa treina funcionários; e apenas $26,5 \%$ tem sistema de CRM, ferramenta indispensável para agilizar processos e auxiliar na gestão de clientes. Como resultado, esta pesquisa tem grande contribuição para o maior conhecimento sobre a fidelização de clientes e como ela pode ser importante para resultados positivos nas organizações.

PALAVRAS-CHAVE: Fidelização de Clientes. Marketing de Relacionamento. Gestão Empresarial.

\begin{abstract}
Nowadays, adopting loyalty programs through relationship marketing has become an important strategy for organizations. The purpose of the article is to analyze business strategies regarding the importance and use of customer loyalty programs. In this way, bibliographic sources were used, such as books and scientific articles. As a research method, data collect were made with managers from cities in the interior of Paraná through the application of 107 questionnaires, sent via Google Forms. Among the variables analyzed, the main findings point out that $91.2 \%$ agree that the company seeks to have a good relationship with its customers, a fact that corroborates that only $9.8 \%$ consider that the company lost customers that were previously loyal. About $78.4 \%$ affirm that the company is aware of the importance of customer loyalty, although $65.7 \%$ claim that they have loyalty strategies, and the use of social networks to win new customers is made by $64.7 \%$ of managers, an important fact due to the constant growth of communication technologies.
\end{abstract}

\footnotetext{
1 Pós Doutor em Gestão Urbano PUCPR. Docente do curso de administração da Universidade Estadual do Centro Oeste - UNICENTRO/PR

2 Discente do curso de administração da Universidade Estadual do Centro Oeste - UNICENTRO/PR

3 Discente do curso de administração da Universidade Estadual do Centro Oeste - UNICENTRO/PR

4 Discente do curso de administração da Universidade Estadual do Centro Oeste - UNICENTRO/PR
} 


\section{RECIMA21 - REVISTA CIENTÍFICA MULTIDISCIPLINAR ISSN 2675-6218}

ESTRATÉGIA DE FIDELIZAÇ̃̃o COMO PRÁTICA EMPRESARIAL PARA CONQUISTA DE CLIENTES Cláudio Luiz Chiusoli, Dyesli Rita de Oliveira de Souza, Elis Regina Cardoso Lecenko, Isabela Wolski Camargo

On the other hand, 59.8\% agree that the company has loyalty and relationship programs, and $40.2 \%$ agree that the company has effective control over who are the loyal customers. As for indicators with less agreement, only 33.3\% mention that the company trains employees, and only $26.5 \%$ have a CRM system, an indispensable tool to streamline processes and help with customer management. As a result, this research has made a major contribution to greater knowledge about customer loyalty and how it can be important for positive results in organizations.

KEYWORDS: Customer loyalty. Marketing of relationship. Business management.

\section{RESUMEN}

Hoy en día, la adopción de programas de fidelización a través del marketing relacional se ha convertido en una estrategia importante para las organizaciones. El propósito del artículo es analizar las estrategias comerciales sobre la importancia y el uso de los programas de fidelización de clientes. De esta forma se utilizaron fuentes bibliográficas, como libros y artículos científicos. Como método de investigación, se realizaron recolecciones junto con los administradores municipales del interior de Paraná mediante la aplicación de 107 cuestionarios, enviados a través de Google Forms. Entre las variables analizadas, los principales hallazgos señalan que el 91,2\% está de acuerdo en que la empresa busca tener una buena relación con sus clientes, hecho que corrobora que solo el 9,8\% considera que la empresa perdió clientes que antes eran leales. Alrededor del 78,4\% afirma que la empresa es consciente de la importancia de la fidelización de los clientes, aunque solo el 65,7\% afirma tener estrategias de fidelización; El 64,7\% de los directivos hace uso de las redes sociales para captar nuevos clientes, hecho importante debido al constante crecimiento de las tecnologías de la comunicación. Por otro lado, el 59,8\% coincide en que la empresa cuenta con programas de fidelización y relación; y el 40,2\% está de acuerdo en que la empresa tiene un control efectivo sobre quiénes son los clientes fieles. Con indicadores de menor acuerdo, solo el 33,3\% menciona que la empresa capacita a los empleados; y solo el $26,5 \%$ tiene un sistema CRM, una herramienta indispensable para agilizar los procesos y ayudar en la gestión de clientes. Como resultado, esta investigación ha hecho una contribución importante a un mayor conocimiento sobre la lealtad del cliente y cómo puede ser importante para obtener resultados positivos en las organizaciones.

PALABRAS CLAVE: Fidelización de clientes. Marketing de relación. Gestión empresarial.

\section{INTRODUÇÃO}

Diante do cenário atual, de amplo crescimento e globalização do mercado, as empresas precisam estar sempre em busca de novas soluções para engajar seus consumidores, os quais, por sua vez, tornam-se cada vez mais exigentes quando buscam por serviços. Uma boa saída é a fidelização de clientes.

Com um mercado extremamente competitivo, onde os consumidores estão sempre rodeados de opções, com muito acesso às informações e sempre buscando por serviços que otimizem seu tempo na correria do dia a dia, é necessário encontrar alternativas que conquistem o cliente não apenas no bolso, mas de tal forma que façam com que ele se torne fiel aos seus serviços (SILVA et al., 2016). Isto pode ser feito de maneira simples e criativa, buscando inovações e tornando a fidelização com o cliente um relacionamento duradouro. 


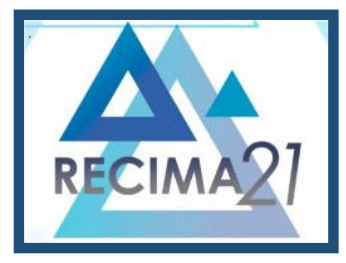

\section{RECIMA21 - REVISTA CIENTÍFICA MULTIDISCIPLINAR ISSN 2675-6218}

A fidelização de clientes é o conjunto de ações que as empresas fazem para fidelizar e reter clientes potenciais, superando suas expectativas, inovando nos produtos, na forma de comunicação, gerando uma frequência e repetição de compra (PAULA; SOUZA, 2017).

Segundo Panosso e Froemming (2015), fidelizar um cliente na organização é um trabalho muito difícil; não é apenas o ato de fazer o cliente voltar a comprar. Deve-se lembrar que o marketing tradicional tem 0 foco em conquistar novos clientes para a empresa, enquanto 0 marketing de relacionamento visa criar, manter e aprimorar fortes relacionamentos com os clientes, elaborando estratégias para atraí-los, e criando relacionamentos duradouros e lucrativos (PAULA; SOUZA, 2017).

A fidelização para algumas empresas fica fora do alcance, pois há muita rotatividade entre os clientes, isso acontece, muitas vezes, por conta de o cliente encontrar outro lugar melhor para realizar as suas compras. $E$ isso faz com que os empresários se questionem sobre o que devem melhorar e como podem fazer com que os clientes não deixem de comprar da empresa; contudo, após a perda do cliente, fica difícil de saber em quais pontos a empresa precisa melhorar e de que maneira ele se sente melhor quando atendido (UNES et al., 2019).

Este estudo se justificativa pelo motivo de demonstrar o quanto as empresas utilizam mecanismo de fidelização de clientes e nortear como uma vantagem competitiva (HOOLEY et al., 2001), uma que vez que, para Gonçalves et al. (2020), tomar a decisão de fidelizar seus clientes é criar linhas e aspectos culturais, reorganizar as estruturas operacionais da organização e agregar maior valor a seus clientes. Atualmente, inovar é palavra-chave no meio empresarial, tornando-se importante também destacada atualização quando o assunto é o bem mais precioso da empresa, os clientes.

Para que se possa ter a resposta neste estudo, as questões quanto ao problema de pesquisa são: Quais são as práticas de programas de fidelização utilizadas pelas empresas que desejam fidelizar seus clientes? E quantos utilizam de programas de relacionamento de fidelidade do cliente e fazem uso do Gerenciamento de Relacionamento com Cliente (CRM)?

Deste modo, o objetivo geral é analisar as estratégias empresariais quanto à importância e o uso de programa de fidelização de clientes. Como objetivos específicos, buscou-se identificar o quanto as empresas, de acordo com os gestores: i) procuram ter um bom relacionamento com seus clientes; ii) têm consciência da importância da fidelização de clientes; iii) possuem estratégias de fidelização de clientes; iv) utilizam as redes sociais para conquistar novos clientes; v) possuem programas de fidelidade e relacionamento aos clientes; vi) possuem controle efetivo de quais são os clientes fiéis; vii) treinam os funcionários para atenderem bem os clientes; viii) têm sistema de CRM; e ix) perderam clientes que antes eram fiéis.

\section{REFERENCIAL TEÓRICO}

Previamente, nessa seção teórica, aborda-se questões a fim de esclarecer assuntos referentes ao tema abordado como: gestão empresarial e marketing de relacionamento. 


\section{RECIMA21 - REVISTA CIENTÍFICA MULTIDISCIPLINAR ISSN 2675-6218}

ESTRATÉGIA DE FIDELIZAÇ̃̃o COMO PRÁTICA EMPRESARIAL PARA CONQUISTA DE CLIENTES Cláudio Luiz Chiusoli, Dyesli Rita de Oliveira de Souza, Elis Regina Cardoso Lecenko, Isabela Wolski Camargo

\section{Gestão empresarial}

Ao longo dos anos as empresas começaram a perceber que o comportamento dos clientes havia mudado, o avanço das transformações tecnológicas fez com que os produtos e serviços fossem se aperfeiçoando, e os clientes passaram a ser mais exigentes com o que estavam adquirindo; para que as empresas não perdessem seus clientes, elas deveriam ter um diferencial competitivo das demais empresas, algo que conquistasse o cliente e o fizesse não só adquirir, e sim voltar à empresa. Quando as empresas perceberam esta mudança, deram-se conta que o relacionamento com seus clientes deve ter um cuidado especial e individual (MOUTELLA, 2004).

Com a finalidade de conquistar os clientes, as empresas devem prestar atenção aos seus tipos de cliente, tais como clientes fiéis convictos (os quais confiam na empresa e sempre estão adquirindo seus produtos); clientes fiéis divididos (aqueles que são fiéis a uma empresa, entretanto possuem outras); clientes fiéis inconstantes (clientes que não estão a todo momento na mesma empresa); e os clientes infiéis (os quais não são fiéis a nenhuma empresa), citam Pereira e Leite (2018).

É importante que as empresas tenham esse controle sobre seus compradores, a fim de saber como estão as estratégias de gerenciamento de sua empresa, para assim ir em busca de seus clientes e entender o motivo de seus comportamentos, de acordo com sua classificação e dessa forma, identificar onde podem melhorar (PEREIRA; LEITE, 2018).

Quando um consumidor vai em busca de um produto ou serviço, ele tem a expectativa de não apenas ser bem atendido e ter um produto ou serviço de qualidade, mas sim de se sentir importante com sua compra; quando isso acontece, ele pode dizer para as pessoas que fez ótimo negócio. Isto é o que as empresas atualmente devem buscar: satisfazer as expectativas dos seus clientes (PEREIRA; LEITE, 2018).

O termo fidelidade vem do latim "fidem" e quer dizer afeição entre pessoas, é um processo em que as empresas utilizam como estratégia para reconhecer o interesse que os clientes têm pela empresa (PEREIRA; LEITE, 2018).

$O$ processo de fidelização do cliente auxilia para que o indivíduo perceba a qualidade envolvida no processo de venda, essa percepção ajuda a empresa a criar um forte vínculo de lealdade com seu público-alvo e, consequentemente, aumentar seu valor no mercado (KONDO et al., 2009).

Nesse sentido, é importante que as empresas trabalhem em busca da fidelização de clientes, tanto quanto em conquistar novos clientes; pois manter seus clientes significa efetivar aqueles que, muitas vezes, ainda não estão fidelizados; para que isso seja possível, as empresas recorrem a estratégias, programas de fidelidade e ao marketing de relacionamento (AUGUSTO; JÚNIOR, 2015). 


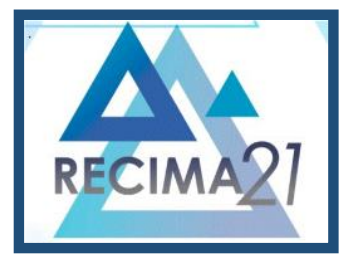

\section{RECIMA21 - REVISTA CIENTÍFICA MULTIDISCIPLINAR ISSN 2675-6218}

\section{Marketing de relacionamento}

Nos tempos atuais o marketing passou a olhar mais pelo lado qualitativo do que quantitativo, pois as pessoas buscam mais por qualidade do que por quantidade de materiais. $O$ cliente tem toda atenção, e sua opinião é de extrema importância para o desenvolvimento do trabalho. Com o avanço tecnológico, ficou ainda mais fácil a realização dos produtos e serviços solicitados; os consumidores passaram a ter maior poder de escolha, podendo optar pelo que mais Ihes agrada, sendo em qualidade e preço. Isso acaba gerando uma maior competitividade entre as empresas em relação ao ganho de clientes e ao relacionamento que estabelecem com eles, para que, com isso, se tornem clientes fixos (GABRIEL, 2010).

SCUSSEL et al. (2017) colocam que o marketing de relacionamento é a utilização de um conjunto de técnicas e processos de marketing, vendas, comunicação e cuidados com o cliente, visando identificá-los de forma individualizada e nominal, criando relacionamentos duradouros e administrando-os para o benefício mútuo. Tendo isso em mente, fica mais fácil descobrir como conquistar um novo cliente apenas com o modo de o tratar e de ver quais são suas necessidades de compra.

O marketing de relacionamento torna-se uma ferramenta imprescindível dentro das empresas, muitas delas buscam seus clientes por meio das redes sociais, Instagram, Facebook etc., com tanta tecnologia e novidades surgindo a todo instante, uma coisa substitui a outra, mas se nesse meio tempo, a empresa investir em um bom relacionamento com seu cliente, dificilmente ele irá trocá-la por outra (SCUSSEL et al., 2017). Desse modo, as informações obtidas precisam ser transformadas pelas empresas em estratégias que auxiliem nas ações direcionadas aos clientes, de modo a propiciar um melhor desempenho por meio do marketing de relacionamento combinado com a tecnologia do CRM (REIS et al., 2016).

$\mathrm{Na}$ literatura de marketing, CRM e marketing de relacionamento têm suas definições como sinônimos, ou seja, esses termos são interligados. Mas ainda assim existem diferenças entre eles, o marketing de relacionamento não reconhece e não busca reconhecer a tecnologia oculta; enquanto o CRM se baseia por ela para se informar e implantar estratégias no marketing de relacionamento (MATOS; MOREIRA, 2019).

A definição de Customer Relationship Management (CRM) é um dos métodos mais sofisticados e eficientes que pode modificar a maneira como as empresas aumentam a rentabilidade dos clientes atuais. Além disso, o uso da Internet como canal de relacionamento e de vendas é facilitado por este novo método, que ainda é praticado por poucas empresas, porém, cujos resultados são amplamente compensadores em clientes mais leais, gerando maior satisfação com a marca e um nível de proximidade nunca antes experimentados (UNES et al., 2019).

Muitos autores definem de formas diferentes o CRM, mas todos mostram e identificam um mesmo propósito, que está relacionado com a conquista de clientes fiéis e de como isso é importante para a empresa. 


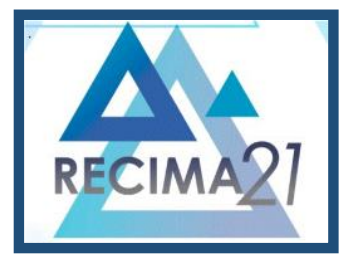

\section{RECIMA21 - REVISTA CIENTÍFICA MULTIDISCIPLINAR ISSN 2675-6218}

Na pratica, o CRM tem o intuito de integrar a tecnologia com as pessoas, buscando uma forma de manter um bom relacionamento com os mesmos, baseando-se em informações dos dados dos clientes. Já na técnica, o CRM é uma tecnologia que automatiza processos, para buscar bons relacionamentos com os clientes e utilizar informações de seus dados pessoais para o bem próprio (REIS et al., 2016).

\section{MÉTODOS E TÉCNICAS DE PESQUISA}

Como método de pesquisa foi realizado um levantamento bibliográfico, e segundo Gil (2017), publicado a partir de estudos relacionados a um tema específico de pesquisa. Para tanto, foram utilizados materiais bibliográficos, como livros, artigos científicos e outras publicações sobre temas de pesquisa.

Quanto à natureza das variáveis foi uma pesquisa quantitativa; e quanto ao objetivo, foi descritiva, sendo que para Knechtel (2014), pesquisa quantitativa trata-se de uma pesquisa que parte de um problema humano ou social, sendo composta de variações medidas em números, que são analisadas com o modo estatístico para alcançar o objetivo de descobrir se as suposições propostas na teoria realmente se sustentam. De acordo com Gil (2017) as pesquisas descritivas têm o objetivo de descrição das características de uma determinada população, fenômeno, ou o estabelecimento de relações entre variáveis, elas realizam pesquisas sociais com a preocupação na atuação prática.

Quanto à população e unidade de observação, segundo Hooley et al. (2001), público-alvo basicamente é um senso de oportunidade de mercado, que direciona as ações de uma organização a uma possibilidade maior de retorno financeiro, capacidade de superação de classe; esse estudo foi realizado junto aos gestores ou proprietários das empresas selecionadas.

Quanto às variáveis e escalas utilizadas, utilizou-se da escala nominal e ordinal. A primeira, segundo Mattar (2014), é aquela em que os números convêm para nomear, identificar e categorizar dados sobre pessoas, objetos ou fatos, são usadas em pesquisas de marketing para nomear, identificar e classificar variáveis como marcas, gênero, tipo de loja, regiões, gosta ou não gosta, ocupação, a única operação é a contagem pela moda. No caso, na pesquisa foi identificado o gênero, faixa etária e o tempo de atuação na empresa pelo participante do estudo.

Já a escala ordinal, de acordo com Mattar (2014), é aquela em que os números servem para nomear, identificar, categorizar, ordenar, segundo um processo de comparação, as pessoas, os objetos, fatos, em relação a uma característica, ela é muito utilizada em pesquisas de marketing em que se deseja obter ordenamento das preferências, opiniões, atitudes e percepções dos consumidores, as únicas medidas que podem ser calculadas são a moda e a mediana. No caso do estudo, foi utilizado a escala de 3 pontos: concordo, indiferente e não concordo.

Quanto à técnica de amostragem, foi definida como não probabilística, que para Mattar (2014) é aquela em que a seleção dos elementos da população para compor a amostra depende, 


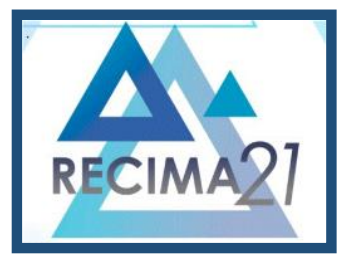

\section{RECIMA21 - REVISTA CIENTÍFICA MULTIDISCIPLINAR ISSN 2675-6218}

ao menos em partes, do julgamento do pesquisador ou do entrevistador no campo; nesse caso, foram investigados 107 gestores de empresas ou proprietários.

Quanto à forma da coleta dos dados, Gil (2017) diz que levantamento é uma forma de se perguntar sobre um comportamento de pessoas que se deseja conhecer e entender. Obtém-se informações com um determinado grupo de pessoas sobre o problema estudado, para depois analisá-las de forma quantitativa e obter conclusões acerca dos dados coletados.

Quanto à forma da abordagem, foi por meio digital, pela web e e-mail, utilizando o Google Forms, apresentando como vantagens que os questionários podem ser enviados com maior velocidade e quantas vezes forem necessárias; maior velocidade também no recebimento das respostas; os questionários podem ser respondidos de acordo com a conveniência e tempo do entrevistado (VIEIRA; CASTRO; JÚNIOR, 2010).

Quanto à procedência dos dados, foram primários, que para Mattar (2014) são aqueles que não foram antes coletados e que são coletados com o propósito de atender às necessidades específicas da pesquisa em andamento.

Quanto ao recorte; foi definido como transversal, que são estudos em que a exposição ao fator ou causa está presente ao efeito no mesmo momento ou intervalo de tempo analisado (HOCHMAN et al.,2005).

Quanto à técnica estatística, a análise dos dados consistiu-se em análises univariadas e bivariadas com base em frequências absolutas e relativas. As medidas de associação foram testadas por meio do teste não paramétrico Qui-Quadrado (SIEGEL; CASTELLAN, 2017).

Tal teste é uma estatística utilizada a fim de avaliar se as observações não pareadas entre duas variáveis são independentes entre si, sendo aplicadas ao nível de significância de 5\%, para testar se deve ou não rejeitar as hipóteses postuladas. Assim, se o p-valor obtido for abaixo de $5 \%$ $(p \leq 0,05)$, as variáveis são independentes, e as hipóteses devem ser rejeitadas; caso contrário, se for acima de $5 \%$, não devem ser rejeitadas.

Ou seja, o teste qui-quadrado foi utilizado para analisar a existência da relação das variáveis investigadas entre os gestores, considerando gênero, faixa etária e tempo de atuação na empresa.

Contido essas informações, as hipóteses da pesquisa foram:

H0: Não há diferença significativa na opinião dos gestores em relação às variáveis investigadas segmentadas por gênero (feminino e masculino).

H1: Não há diferença significativa na opinião dos gestores em relação às variáveis investigadas segmentadas por faixa etária (até 30 anos, de 31 a 40 anos e acima de 40 anos).

H2: Não há diferença significativa na opinião dos gestores em relação às variáveis investigadas segmentadas por tempo de atuação na empresa (até 1 ano, de 2 a 5 anos, de 6 a 10 anos e acima de 10 anos).

\section{RESULTADOS E DISCUSSÃO}




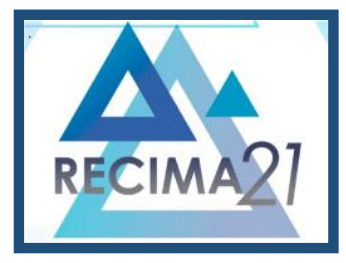

\section{RECIMA21 - REVISTA CIENTÍFICA MULTIDISCIPLINAR ISSN 2675-6218}

Nessa seção, realiza-se a análise dos resultados, sendo composta por 13 Quadros e cruzamentos por gênero e faixa etária. Nos Quadros 1 a 3 têm-se, primeiramente, os dados pessoais (perfil por gênero, faixa etária e tempo de atuação na empresa); e após, do Quadro 4 ao 12 , os resultados alcançados conforme os objetivos propostos; por fim, o Quadro 13 é referente aos resultados do teste Qui-Quadrado, para mostrar a rejeição ou não das hipóteses H0, H1 e H2 investigadas.

O Quadro 1 refere-se à variável "Gênero do respondente"; mostra um p-valor de 0,000 para a hipótese $\mathrm{H} 1$, e um p-valor de 0,000 para a hipótese $\mathrm{H} 2$, sugerindo que as hipóteses $\mathrm{H} 1$ e $\mathrm{H} 2$ devem ser rejeitadas, ou seja, nos cruzamentos dos dados por faixa etária e tempo de atuação na empresa, apresentam diferenças significativas entre os perfis dos respondentes.

Assim, considerando essas diferenças estatísticas apontadas pelo teste do Qui-Quadrado, o perfil dos entrevistados com relação ao gênero revela que a maioria $(66,7 \%)$ pertence ao gênero feminino, sendo predominante para o sexo feminino a faixa etária de até 30 anos (83,3\%), seguida pelo intervalo de 31 a 40 anos $(77,4 \%)$, e o restante $(31,0 \%)$ pertence à faixa etária de 40 anos ou mais, revelando um público feminino mais jovem.

Quanto ao tempo de serviço, entre as mulheres, a maioria está em até 1 ano $(91,3 \%)$, seguida de 2 a 5 anos (72,4\%), revelando uma recente entrada nas empresas atuais.

Tratando-se do público masculino (33,3\%), sua maioria $(69,0 \%)$ pertence à faixa etária de 40 ou mais anos, seguida pela faixa etária de 31 a 40 anos (22,6\%), e até 30 anos (16,7\%), revelando um público masculino mais velho e, possivelmente, mais maduro quanto à forma de gestão de uma empresa.

Quanto ao tempo de serviço masculino, há uma grande predominância, de $66,7 \%$, em mais de 10 anos, seguida pelo intervalo de 6 a 10 anos, com $30,8 \%$, sugerindo que o público masculino está há mais tempo em suas empresas atuais.

\section{Quadro 1 - Gênero}

\begin{tabular}{|c|c|c|c|c|c|c|c|c|}
\hline & \multicolumn{3}{|c|}{ Faixa etária } & \multicolumn{4}{|c|}{ Tempo de atuação na empresa } & \multirow[b]{2}{*}{ Total } \\
\hline Gênero & Até $\mathbf{3 0}$ & $31 / 40$ & $40+$ & Até 1 & $2 / 5$ & $6 / 10$ & $10+$ & \\
\hline Feminino & $83,3 \%$ & $77,4 \%$ & $31,0 \%$ & $91,3 \%$ & $72,4 \%$ & $69,2 \%$ & $33,3 \%$ & $66,7 \%$ \\
\hline Masculino & $16,7 \%$ & $22,6 \%$ & $69,0 \%$ & $8,7 \%$ & $27,6 \%$ & $30,8 \%$ & $66,7 \%$ & $33,3 \%$ \\
\hline Total Geral & $100,0 \%$ & $100,0 \%$ & $100,0 \%$ & $100,0 \%$ & $100,0 \%$ & $100,0 \%$ & $100,0 \%$ & $100,0 \%$ \\
\hline
\end{tabular}

O Quadro 2 refere-se à variável "Faixa etária do respondente"; mostra um p-valor de 0,000 para a hipótese $\mathrm{H} 0$, um p-valor de 0,000 para a hipótese $\mathrm{H} 2$, sugerindo que as hipóteses $\mathrm{H} 0$ e $\mathrm{H} 2$ devem ser rejeitadas; ou seja, há diferença estatística significativa entre os perfis dos respondentes de acordo com os cruzamentos quanto ao gênero e tempo de atuação na empresa.

Desse modo, considerando essas diferenças estatísticas apontadas pelo teste do QuiQuadrado, no perfil dos entrevistados com relação à faixa etária, evidencia-se que $41,2 \%$ dos 


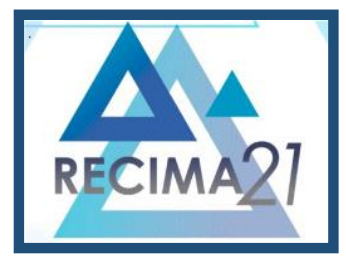

\section{RECIMA21 - REVISTA CIENTÍFICA MULTIDISCIPLINAR ISSN 2675-6218}

entrevistados pertence à faixa etária de até 30 anos, seguido da faixa etária de 31 a 40 anos $(30,4 \%)$ e 40 anos ou mais (28,4\%), identificando uma predominância mais jovem.

Os resultados ainda apontam uma predominância no tempo de atuação na empresa de mais de 10 anos $(91,7 \%)$ dos entrevistados na faixa etária de 40 ou mais; e na outra ponta, respondentes com até 1 ano de tempo de atuação na empresa (87,0\%), em que predomina a faixa etária de até 30 anos.

Quadro 2 - Faixa etária

\begin{tabular}{|c|c|c|c|c|c|c|c|}
\hline & \multicolumn{2}{|c|}{ Gênero } & \multicolumn{2}{c|}{ Tempo de atuação na empresa } & \\
\hline Faixa etária & Feminino & Masculino & Até 1 & $\mathbf{2} / \mathbf{5}$ & $\mathbf{6} / \mathbf{1 0}$ & $\mathbf{1 0}+$ & Total \\
\hline Até 30 & $51,5 \%$ & $20,6 \%$ & $87,0 \%$ & $62,1 \%$ & $11,5 \%$ & $4,2 \%$ & $41,2 \%$ \\
\hline $31 / 40$ & $35,3 \%$ & $20,6 \%$ & $8,7 \%$ & $37,9 \%$ & $65,4 \%$ & $4,2 \%$ & $30,4 \%$ \\
\hline $40+$ & $13,2 \%$ & $58,8 \%$ & $4,3 \%$ & $0,0 \%$ & $23,1 \%$ & $91,7 \%$ & $28,4 \%$ \\
\hline Total Geral & $100,0 \%$ & $100,0 \%$ & $100,0 \%$ & $100,0 \%$ & $100,0 \%$ & $100,0 \%$ & $100,0 \%$ \\
\hline
\end{tabular}

Fonte: Dados da pesquisa (2020)

O Quadro 3 refere-se à variável "Tempo de atuação na empresa do respondente"; mostra um p-valor de 0,000 para a hipótese H0, um p-valor de 0,000 para a hipótese $\mathrm{H} 1$, o que sugere que as hipóteses $\mathrm{H} 1$ e $\mathrm{H} 2$ devem ser rejeitadas, por apresentarem diferenças estatísticas significativas entre os perfis dos respondentes quanto ao gênero e faixa etária.

Ainda considerando as diferenças estatísticas apontadas pelo teste do Qui-Quadrado nesse perfil dos entrevistados, em relação ao tempo de atuação na empresa, há uma predominância no intervalo de 2 a 5 anos (28,4\%), seguido por 6 a 10 anos $(25,5 \%)$, mais de 10 anos $(23,5 \%)$ e até 1 ano $(22,5 \%)$.

Observa-se ainda que $47,1 \%$ dos entrevistados pertencentes ao sexo masculino estão há mais de 10 anos à frente da atividade da empresa, enquanto as respondentes mulheres $(30,9 \%)$ encontram-se em até um ano, e também 30,9\% atuam de 2 a 5 anos. Quanto à faixa etária, a maioria $(75,9 \%)$ com 40 ou mais anos está a mais de 10 anos atuando na empresa.

Quadro 3 - Tempo de atuação na empresa

\begin{tabular}{|c|c|c|c|c|c|c|}
\hline & \multicolumn{2}{|c|}{ Gênero } & \multicolumn{3}{c|}{ Faixa etária } & \\
\hline Tempo serviço & Feminino & Masculino & Até 30 & $\mathbf{3 1 / 4 0}$ & $\mathbf{4 0}+$ & Total \\
\hline Até 1 & $30,9 \%$ & $5,9 \%$ & $47,6 \%$ & $6,5 \%$ & $3,4 \%$ & $22,5 \%$ \\
\hline De $2 / 5$ & $30,9 \%$ & $23,5 \%$ & $42,9 \%$ & $35,5 \%$ & $0,0 \%$ & $28,4 \%$ \\
\hline De 6/10 & $26,5 \%$ & $23,5 \%$ & $7,1 \%$ & $54,8 \%$ & $20,7 \%$ & $25,5 \%$ \\
\hline $10+$ & $11,8 \%$ & $47,1 \%$ & $2,4 \%$ & $3,2 \%$ & $75,9 \%$ & $23,5 \%$ \\
\hline Total Geral & $100,0 \%$ & $100,0 \%$ & $100,0 \%$ & $100,0 \%$ & $100,0 \%$ & $100,0 \%$ \\
\hline
\end{tabular}

Fonte: Dados da pesquisa (2020)

O Quadro 4 refere-se à variável " $A$ minha empresa tem consciência da importância da fidelização de clientes"; mostra um p-valor de 0,003 para a hipótese H0, um p-valor de 0,003 para a hipótese $\mathrm{H} 1$, e um p-valor de 0,1128 para a hipótese $\mathrm{H} 2$, sugerindo que as hipóteses $\mathrm{H} 1$ e $\mathrm{H} 2$ 


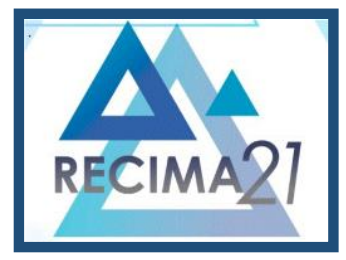

\section{RECIMA21 - REVISTA CIENTÍFICA MULTIDISCIPLINAR ISSN 2675-6218}

devem ser rejeitadas, ou seja, nos cruzamentos dos dados por gênero e faixa etária há diferenças significativas entre as opiniões dos gestores; e a hipótese $\mathrm{H} 2$ não deve ser rejeitada.

Ao questionar os empresários, gestores e gerentes participantes da pesquisa sobre a importância da fidelização de clientes e o quanto sua empresa sabe sobre o assunto, $78,4 \%$ concordam que estão por dentro do assunto; apenas 10,8\% discordam.

Também pode-se notar que o público feminino demonstrou maior predominância nas respostas concordantes $(88,2 \%)$, já o público masculino teve $58,8 \%$ de votos para concordo e $20,6 \%$ para discordo, sugerindo que as gestoras do gênero feminino possuem mais informações sobre o assunto. Em relação à faixa etária, a maior predominância $(97,6 \%)$ está entre os gestores mais jovens, faixa de até 30 anos; e em tempo de serviço, a maioria (95,7\%) está atuando na empresa há cerca de até 1 ano. Considerando que 8 entre 10 entrevistados afirmaram ter ciência da fidelização de clientes, sugere-se que o conjunto de ações que as empresas fazem para fidelizar e reter clientes potenciais, ao superar suas expectativas e inovando nos produtos, como forma de comunicação, pode gerar uma repetição de compra (PAULA; SOUZA, 2017).

Quadro 4 - A minha empresa tem consciência da importância da fidelização de clientes

\begin{tabular}{|c|c|c|c|c|c|c|c|c|c|c|}
\hline & Gênero & \multicolumn{3}{|c|}{ Faixa etária } & \multicolumn{3}{c|}{ Tempo de atuação na empresa } & \\
\hline Escala & Fem. & Masc. & Até 30 & $\mathbf{3 1 / 4 0}$ & $\mathbf{4 0 +}$ & Até 1 & $\mathbf{2} / \mathbf{5}$ & $\mathbf{6} / \mathbf{1 0}$ & $\mathbf{1 0}+$ & Total \\
\hline Concordo & $88,2 \%$ & $58,8 \%$ & $97,6 \%$ & $77,4 \%$ & $51,7 \%$ & $95,7 \%$ & $86,2 \%$ & $73,1 \%$ & $58,3 \%$ & $78,4 \%$ \\
\hline Indiferente & $5,9 \%$ & $20,6 \%$ & $0,0 \%$ & $9,7 \%$ & $27,6 \%$ & $0,0 \%$ & $6,9 \%$ & $11,5 \%$ & $25,0 \%$ & $10,8 \%$ \\
\hline Discordo & $5,9 \%$ & $20,6 \%$ & $2,4 \%$ & $12,9 \%$ & $20,7 \%$ & $4,3 \%$ & $6,9 \%$ & $15,4 \%$ & $16,7 \%$ & $10,8 \%$ \\
\hline Total & $100,0 \%$ & $100,0 \%$ & $100,0 \%$ & $100,0 \%$ & $100,0 \%$ & $100,0 \%$ & $100,0 \%$ & $100,0 \%$ & $100,0 \%$ & $100,0 \%$ \\
\hline
\end{tabular}

Fonte: Dados da pesquisa (2020)

O Quadro 5 refere-se à variável "A minha empresa possui estratégias de fidelização de clientes"; mostra um p-valor de 0,001 para a hipótese $\mathrm{H} 0$, um p-valor de 0,000 para a hipótese $\mathrm{H} 1$, e um p-valor de 0,042 para a hipótese H2. Diante dos resultados do teste estatístico, sugere-se que as hipóteses $\mathrm{H} 0, \mathrm{H} 1$ e $\mathrm{H} 2$ devem ser rejeitadas, pelo motivo de identificar diferenças de opiniões entres os gestores participantes no estudo.

Assim, o fato das empresas possuírem estratégias para fidelização de seus clientes, no estudo, demonstra um resultado de $65,7 \%$ de concordância, um índice elevado; porém, 18,6\% dos entrevistados afirmam que suas empresas não possuem essas estratégias, o que poderia ser utilizado para melhorar o desempenho da empresa.

Em relação ao gênero dos participantes, $75,0 \%$ do público feminino e $47,1 \%$ do masculino concordam; houve maior discordância entre o público masculino (38,2\%), contra apenas $8,8 \%$ do público feminino. Quanto à faixa etária, o público pertencente à faixa de 31 a 40 anos foi o que mais afirmou possuir essas estratégias em sua empresa (74,2\%); quanto ao tempo de atuação na empresa, a maior predominância foi no período de até 1 ano $(73,9 \%)$, demonstrando que o público ainda jovem e que está há pouco tempo em suas empresas tem maior tendências de desenvolver a fidelização em seus trabalhos. 


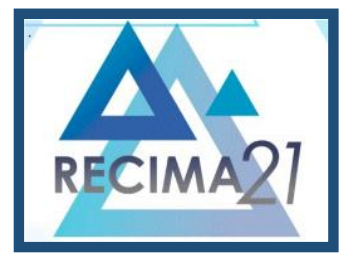

\section{RECIMA21 - REVISTA CIENTÍFICA MULTIDISCIPLINAR ISSN 2675-6218}

Diante dos resultados, verificou-se distantes opiniões conforme perfil dos gestores, mas de todo modo, torna-se importante que as empresas trabalhem em busca da fidelização de clientes, seja para conquistar novos clientes ou para manter os clientes atuais mediante programas de fidelidade e ao marketing de relacionamento (AUGUSTO; JÚNIOR, 2015).

Quadro 5 - A minha empresa possui estratégias de fidelização de clientes

\begin{tabular}{|c|c|c|c|c|c|c|c|c|c|c|}
\hline & Gênero & \multicolumn{3}{|c|}{ Faixa etária } & \multicolumn{2}{c|}{ Tempo de atuação na empresa } & \\
\hline Escala & Fem. & Masc. & Até 30 & $\mathbf{3 1 / 4 0}$ & $\mathbf{4 0}+$ & Até 1 & $\mathbf{2} / \mathbf{5}$ & $\mathbf{6} / \mathbf{1 0}$ & $\mathbf{1 0}+$ & Total \\
\hline Concordo & $75,0 \%$ & $47,1 \%$ & $73,8 \%$ & $74,2 \%$ & $44,8 \%$ & $73,9 \%$ & $69,0 \%$ & $69,2 \%$ & $50,0 \%$ & $65,7 \%$ \\
\hline Indiferente & $16,2 \%$ & $14,7 \%$ & $23,8 \%$ & $9,7 \%$ & $10,3 \%$ & $26,1 \%$ & $24,1 \%$ & $0,0 \%$ & $12,5 \%$ & $15,7 \%$ \\
\hline Discordo & $8,8 \%$ & $38,2 \%$ & $2,4 \%$ & $16,1 \%$ & $44,8 \%$ & $0,0 \%$ & $6,9 \%$ & $30,8 \%$ & $37,5 \%$ & $18,6 \%$ \\
\hline Total & $100,0 \%$ & $100,0 \%$ & $100,0 \%$ & $100,0 \%$ & $100,0 \%$ & $100,0 \%$ & $100,0 \%$ & $100,0 \%$ & $100,0 \%$ & $100,0 \%$ \\
\hline
\end{tabular}

Fonte: Dados da pesquisa (2020)

O Quadro 6 faz referência à variável " $A$ minha empresa procura ter um bom relacionamento com seus clientes"; mostra um $\mathrm{p}$-valor de 0,015 para a hipótese $\mathrm{H} 0$, um $\mathrm{p}$-valor de 0,684 para a hipótese H1, e um p-valor de 0,470 para a hipótese H2. Dessa forma, a hipótese H0 deve ser rejeitada, enquanto que as hipóteses $\mathrm{H} 1$ e $\mathrm{H} 2$ não devem ser rejeitadas.

Observa-se as respostas dadas pelos participantes da pesquisa com relação à busca constante, por parte da empresa, para conquistar um bom relacionamento com seus clientes; $91,2 \%$ respondeu positivamente.

O público feminino mostrou um resultado de $97,1 \%$ para concordo, indicando uma gestão mais preocupada com o relacionamento com seus clientes. Já o público masculino teve uma resposta de 79,4\% para concordo.

Em relação à faixa etária, todos os grupos demonstraram respostas concordantes com bons índices, sendo de 92,9\% entre os respondentes com até 30 anos; de 93,5\% entre os de 31 a 40 anos; e $86,20 \%$ entre os de 40 ou mais, o que demonstra que gestores de todas as idades se preocupam com o relacionamento com seus clientes. Quanto ao tempo de atuação na empresa, também houve um alto nível de concordância em todos os intervalos, sendo de $95,7 \%$ entre os que estão há até 1 ano; $96,6 \%$ entre os de 2 a 5 anos; $80,8 \%$ entre os de 6 a 10 anos; e $91,70 \%$ entre os que estão há mais de 10 anos.

Por meio das redes de contato, o gestor do gênero feminino demonstra apresentar maior sensibilidade a essa questão, pelas possibilidades constantes de trocas de mensagens e amizades realizadas, com isso faz com que a empresa invista em um bom relacionamento a ponto de conquistar a fidelização do cliente (SANTOS; DIOGENES, 2019).

Quadro 6 - A minha empresa procura ter um bom relacionamento com seus clientes

\begin{tabular}{|c|c|c|c|c|c|c|c|c|c|c|}
\hline & \multicolumn{2}{|c}{ Gênero } & \multicolumn{3}{c|}{ Faixa etária } & \multicolumn{3}{c|}{ Tempo de atuação na empresa } & \\
\hline Escala & Fem. & Masc. & Até 30 & $\mathbf{3 1 / 4 0}$ & $\mathbf{4 0}+$ & Até 1 & $\mathbf{2} / \mathbf{5}$ & $\mathbf{6} / \mathbf{1 0}$ & $\mathbf{1 0}+$ & Total \\
\hline Concordo & $97,1 \%$ & $79,4 \%$ & $92,9 \%$ & $93,5 \%$ & $86,2 \%$ & $95,7 \%$ & $96,6 \%$ & $80,8 \%$ & $91,7 \%$ & $91,2 \%$ \\
\hline Indiferente & $2,9 \%$ & $17,6 \%$ & $4,8 \%$ & $6,5 \%$ & $13,8 \%$ & $4,3 \%$ & $3,4 \%$ & $15,4 \%$ & $8,3 \%$ & $7,8 \%$ \\
\hline Discordo & $0,0 \%$ & $2,9 \%$ & $2,4 \%$ & $0,0 \%$ & $0,0 \%$ & $0,0 \%$ & $0,0 \%$ & $3,8 \%$ & $0,0 \%$ & $1,0 \%$ \\
\hline
\end{tabular}




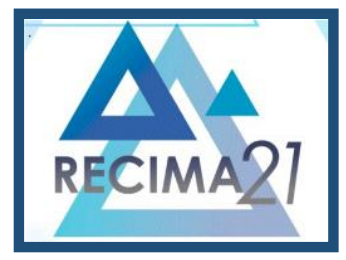

\section{RECIMA21 - REVISTA CIENTÍFICA MULTIDISCIPLINAR ISSN 2675-6218}

ESTRATÉGIA DE FIDELIZAC̄̃̃ COMO PRÁTICA EMPRESARIAL PARA CONQUISTA DE CLIENTES Cláudio Luiz Chiusoli, Dyesli Rita de Oliveira de Souza, Elis Regina Cardoso Lecenko, Isabela Wolski Camargo

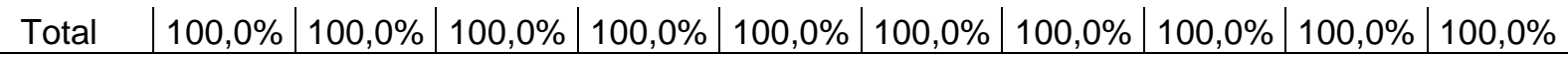
Fonte: Dados da pesquisa (2020)

O Quadro 7 é relacionado à variável "A minha empresa treina os funcionários para atender bem os clientes"; mostra um p-valor de 0,019 para a hipótese $\mathrm{H} 0$, um $\mathrm{p}$-valor de 0,001 para a hipótese $\mathrm{H} 1$, e um p-valor de 0,000 para a hipótese $\mathrm{H} 2$, sugerindo que as três hipóteses $\mathrm{H} 0, \mathrm{H} 1 \mathrm{e}$ H2 devem ser rejeitadas. Ou seja, na segmentação dos dados por gênero, faixa etária e tempo de atuação na empresa, há opiniões distintas, considerando a aplicação do teste estatístico.

Assim, conforme as informações sobre as empresas possuírem treinamentos para que seus funcionários prestem um bom atendimento a seus clientes, somente $33,3 \%$ concordaram. Sendo este um ponto que poderia ajudar grandemente as empresas a melhorarem seu relacionamento com os clientes.

Com relação ao gênero dos participantes, o público feminino teve um maior índice de concordância (42,6\%), enquanto entre o masculino apenas 14,7\% concordaram. A faixa etária que mais afirmou positivamente foi a de até 30 anos (54,8\%), revelando ainda que $65,5 \%$ dos respondentes na faixa etária de 40 anos ou mais discordaram. Já em relação ao tempo de atuação na empresa, houve $56,5 \%$ de concordância entre os respondentes com até 1 ano de atuação; e a maior diferença está no intervalo de 6 a 10 anos, onde 73,1\% discordaram.

Considerando os achados nesse questionamento sobre 0 atendimento e verificado que existe divergências de opiniões, ficou evidente que as gestoras mulheres, de menor faixa etária e com menor tempo de atuação na empresa são as que mais apresentaram essa preocupação. Situação que é primordial para que o atendimento seja um diferencial da empresa em relação à concorrência; nesse sentido, treinar, motivar e um bom clima organizacional podem auxiliar na melhoria do desempenho dos funcionários em atenção aos clientes (AGUIAR; ANJOS, 2017).

Quadro 7 - A minha empresa treina os funcionários para atender bem os clientes

\begin{tabular}{|c|c|c|c|c|c|c|c|c|c|c|}
\hline & \multicolumn{2}{|c|}{ Gênero } & \multicolumn{3}{|c|}{ Faixa etária } & \multicolumn{4}{|c|}{ Tempo de atuação na empresa } & \multirow[b]{2}{*}{ Total } \\
\hline Escala & Fem. & Masc. & Até 30 & $31 / 40$ & $40+$ & Até 1 & $2 / 5$ & $6 / 10$ & $10+$ & \\
\hline Concordo & $42,6 \%$ & $14,7 \%$ & $54,8 \%$ & $25,8 \%$ & $10,3 \%$ & $56,5 \%$ & $41,4 \%$ & $23,1 \%$ & $12,5 \%$ & $3 \%$ \\
\hline Indiferente & $17,6 \%$ & $26,5 \%$ & $19,0 \%$ & $19,4 \%$ & $24,1 \%$ & $8,7 \%$ & $34,5 \%$ & $3,8 \%$ & $33,3 \%$ & $20,6 \%$ \\
\hline Discordo & $39,7 \%$ & $58,8 \%$ & $26,2 \%$ & $54,8 \%$ & $65,5 \%$ & $34,8 \%$ & $24,1 \%$ & $73,1 \%$ & $54,2 \%$ & $46,1 \%$ \\
\hline Total & $100,0 \%$ & $100,0 \%$ & $100,0 \%$ & $100,0 \%$ & $100,0 \%$ & $100,0 \%$ & $100,0 \%$ & $100,0 \%$ & $100,0 \%$ & $100,0 \%$ \\
\hline
\end{tabular}

O Quadro 8 se refere à variável "A minha empresa possui programas de fidelidade $e$ relacionamento aos clientes"; mostra um p-valor de 0,000 para a hipótese $\mathrm{H} 0$, um $\mathrm{p}$-valor de 0,009 para a hipótese $\mathrm{H} 1$, e um p-valor de 0,159 para a hipótese $\mathrm{H} 2$. Diante do teste aplicado, as hipóteses $\mathrm{H} 0$ e $\mathrm{H} 1$ devem ser rejeitadas, e a hipótese $\mathrm{H} 2$ não deve ser rejeitada.

Questionados sobre a empresa possuir programas de fidelidade e relacionamento, observa-se que $59,8 \%$ afirmaram possuir, revelando uma predominância em empresas que 


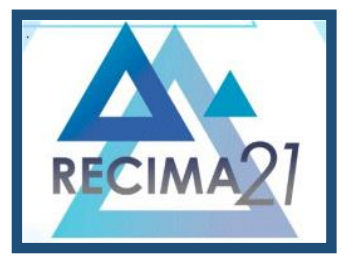

\section{RECIMA21 - REVISTA CIENTÍFICA MULTIDISCIPLINAR ISSN 2675-6218}

adotam esses programas. No público feminino, a maioria, com 75,0\%, concordou, enquanto entre o público masculino o índice cai para $29,4 \%$ de concordância.

Quanto à faixa etária, a maioria que afirma possuir programas está no intervalo de faixas etária de 31 a 40 anos $(71,0 \%)$, e até 30 anos (66,7\%). Nota-se que o inverso ocorre entre os respondentes de 40 anos ou mais, entre os quais $51,7 \%$ afirmaram não possuir programas de fidelidade.

Em relação ao tempo de atuação na empresa, pode-se observar uma maior predominância de concordância entre os gestores que atuam na empresa entre 2 e 5 anos (69,0\%), e um menor índice entre os gestores com mais de 10 anos de empresa $(41,7 \%)$.

O estudo aponta que 6 entre 10 empresas consultadas afirmaram que possuem um programa de fidelidade e relacionamento, mesmo que não seja um sistema tão completo, visto que basta ter informações básicas do banco de dados como: nome completo, CPF, endereço, telefone, valor gasto, frequência de compra, perfil demográfico na plataforma on-line que poder ser realizado por meio do cadastro até pelos próprios clientes (SOUZA JUNIOR; SARFATI, 2020).

Quadro 8 - A minha empresa possui programas de fidelidade e relacionamento aos clientes

\begin{tabular}{|c|c|c|c|c|c|c|c|c|c|c|}
\hline & Gênero & \multicolumn{3}{|c|}{ Faixa etária } & \multicolumn{3}{c|}{ Tempo de atuação na empresa } & \\
\hline Escala & Fem. & Masc. & Até 30 & $\mathbf{3 1 / 4 0}$ & $\mathbf{4 0}+$ & Até 1 & $\mathbf{2} / \mathbf{5}$ & $\mathbf{6} / \mathbf{1 0}$ & $\mathbf{1 0}+$ & Total \\
\hline Concordo & $75,0 \%$ & $29,4 \%$ & $66,7 \%$ & $71,0 \%$ & $37,9 \%$ & $65,2 \%$ & $69,0 \%$ & $61,5 \%$ & $41,7 \%$ & $59,8 \%$ \\
\hline Indiferente & $7,4 \%$ & $26,5 \%$ & $16,7 \%$ & $12,9 \%$ & $10,3 \%$ & $8,7 \%$ & $20,7 \%$ & $7,7 \%$ & $16,7 \%$ & $13,7 \%$ \\
\hline Discordo & $17,6 \%$ & $44,1 \%$ & $16,7 \%$ & $16,1 \%$ & $51,7 \%$ & $26,1 \%$ & $10,3 \%$ & $30,8 \%$ & $41,7 \%$ & $26,5 \%$ \\
\hline Total & $100,0 \%$ & $100,0 \%$ & $100,0 \%$ & $100,0 \%$ & $100,0 \%$ & $100,0 \%$ & $100,0 \%$ & $100,0 \%$ & $100,0 \%$ & $100,0 \%$ \\
\hline
\end{tabular}

O Quadro 9 se refere à variável " $A$ minha empresa possui controle efetivo de quais são os clientes fiéis"; mostra um p-valor de 0,072 para a hipótese H0, um p-valor de 0,004 para a hipótese $\mathrm{H} 1$, e um $p$-valor de 0,010 para a hipótese $\mathrm{H} 2$, sugerindo que a hipótese $\mathrm{H} 0$ não deve ser rejeitada, e as hipóteses $\mathrm{H} 1$ e $\mathrm{H} 2$ devem ser rejeitadas.

O Quadro 9 representa as respostas a respeito se os gestores possuem um controle efetivo de quais são seus clientes fiéis. Nesse item, observa-se que 40,2\% concordam com essa frase, e apenas $21,6 \%$ discordaram, porém houve uma porcentagem relevante para votos de indiferente, com $38,2 \%$. Isso provavelmente revela que nem todas as empresas estão organizadas em fazer esse controle.

Baseado nesses indicadores, criar uma proposta de valorar o produto/serviço pode gerar a fidelização e a sustentação do negócio por meio de um bom programa de marketing de relacionamento, pois verifica-se que ainda há uma lacuna conceitual quanto à compreensão de sua definição e suas práticas (MATOS; MOREIRA, 2019). Em relação ao gênero feminino, 47,1\% concordaram com a afirmação; já entre os homens, apenas $26,5 \%$ concordaram com a questão, e $41,2 \%$ demonstraram ser indiferentes. Para a faixa etária, a maior predominância foi em até 30 anos, onde 59,5\% concordaram; e quanto ao tempo de serviço na empresa, a maior predominância foi no intervalo de até 1 ano, onde $69,6 \%$ concordaram, porém, nota-se uma 


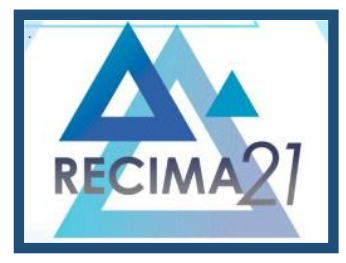

\section{RECIMA21 - REVISTA CIENTÍFICA MULTIDISCIPLINAR ISSN 2675-6218}

grande relevância para a resposta de indiferente entre os respondentes com tempo de serviço de 6 a 10 anos $(53,8 \%)$.

Quadro 9 - A minha empresa possui controle efetivo de quais são os clientes fiéis

\begin{tabular}{|c|c|c|c|c|c|c|c|c|c|c|}
\hline & \multicolumn{2}{|c|}{ Gênero } & \multicolumn{3}{c|}{ Faixa etária } & \multicolumn{3}{c|}{ Tempo de atuaça na empresa } & \\
\hline Escala & Fem. & Masc. & Até 30 & $\mathbf{3 1 / 4 0}$ & $\mathbf{4 0}+$ & Até 1 & $\mathbf{2} / \mathbf{5}$ & $\mathbf{6} / \mathbf{1 0}$ & $\mathbf{1 0}+$ & Total \\
\hline Concordo & $47,1 \%$ & $26,5 \%$ & $59,5 \%$ & $25,8 \%$ & $27,6 \%$ & $69,6 \%$ & $41,4 \%$ & $23,1 \%$ & $29,2 \%$ & $40,2 \%$ \\
\hline Indiferente & $36,8 \%$ & $41,2 \%$ & $31,0 \%$ & $51,6 \%$ & $34,5 \%$ & $17,4 \%$ & $44,8 \%$ & $53,8 \%$ & $33,3 \%$ & $38,2 \%$ \\
\hline Discordo & $16,2 \%$ & $32,4 \%$ & $9,5 \%$ & $22,6 \%$ & $37,9 \%$ & $13,0 \%$ & $13,8 \%$ & $23,1 \%$ & $37,5 \%$ & $21,6 \%$ \\
\hline Total & $100,0 \%$ & $100,0 \%$ & $100,0 \%$ & $100,0 \%$ & $100,0 \%$ & $100,0 \%$ & $100,0 \%$ & $100,0 \%$ & $100,0 \%$ & $100,0 \%$ \\
\hline
\end{tabular}

Fonte: Dados da pesquisa (2020)

O Quadro 10 se refere à variável "A minha empresa perdeu clientes que antes eram fiéis"; mostra um p-valor de 0,223 para a hipótese H0, um p-valor de 0,720 para a hipótese H1, e um pvalor de 0,027 para a hipótese $\mathrm{H} 2$. Assim, as hipóteses $\mathrm{H} 0$ e $\mathrm{H} 1$ não devem ser rejeitadas. Já a hipótese $\mathrm{H} 2$ deve ser rejeitada, por apontar diferença significativa entre as respostas quanto ao tempo de atuação na empresa.

Nesse questionamento, $47,1 \%$ dos gestores opinaram serem indiferentes em perder clientes; por outro lado, $43,1 \%$ discordaram, e apenas $9,8 \%$ concordaram, o que mostra que esse pode ser um ponto mais explorado dentro das empresas, de forma a identificar os reais desejos de seus compradores, e esse indicador aponta de certa forma que um baixo índice considera que os clientes deixaram de compram na empresa.

Entre o gênero feminino, a predominância foi de $48,5 \%$ para votos em discordo, já no gênero masculino, a maioria diz ser indiferente, com 52,9\%. Com relação à faixa etária, a predominância foi em indiferente entre os respondentes com 40 anos ou mais (55,2\%). E quanto ao tempo de atuação na empresa, a maior predominância foi para discordo, com $69,6 \%$, entre os respondentes com até um ano de empresa.

Baseado na opinião dos gestores em relação à questão da fidelidade, é importante destacar que nem sempre um cliente satisfeito é um cliente leal com a marca do produto ou serviço, desse modo, manter a fidelidade significa descobrir não apenas o que ele deseja, mas cabe às empresas entender por meio de estudos os desejos individuais e inconsciente de seus clientes (PAULA; SOUZA, 2017).

Quadro 10 - A minha empresa perdeu clientes que antes eram fiéis

\begin{tabular}{|c|c|c|c|c|c|c|c|c|c|c|}
\hline & \multicolumn{2}{|c|}{ Gênero } & \multicolumn{3}{|c|}{ Faixa etária } & \multicolumn{4}{|c|}{ Tempo de atuação na empresa } & \multirow[b]{2}{*}{ Total } \\
\hline Escala & Fem. & Masc. & Até $\mathbf{3 0}$ & $31 / 40$ & $40+$ & Até 1 & $2 / 5$ & $6 / 10$ & $10+$ & \\
\hline Concordo & $7,4 \%$ & $14,7 \%$ & $11,9 \%$ & $6,5 \%$ & $10,3 \%$ & $4,3 \%$ & $20,7 \%$ & $0,0 \%$ & $12,5 \%$ & $9,8 \%$ \\
\hline Indiferente & $44,1 \%$ & $52,9 \%$ & $40,5 \%$ & $48,4 \%$ & $55,2 \%$ & $26,1 \%$ & $55,2 \%$ & $50,0 \%$ & $54,2 \%$ & $1 \%$ \\
\hline Discordo & $48,5 \%$ & $32,4 \%$ & $47,6 \%$ & $45,2 \%$ & $34,5 \%$ & $69,6 \%$ & $24,1 \%$ & $\%$ & $\%$ & $1 \%$ \\
\hline Total & $100,0 \%$ & $100,0 \%$ & $100,0 \%$ & $100,0 \%$ & $100,0 \%$ & $100,0 \%$ & $100,0 \%$ & $100,0 \%$ & $100,0 \%$ & $100,0 \%$ \\
\hline
\end{tabular}




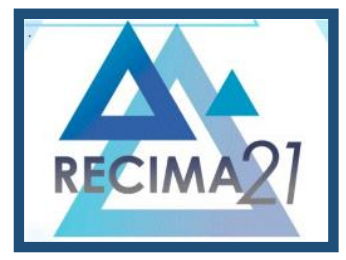

\section{RECIMA21 - REVISTA CIENTÍFICA MULTIDISCIPLINAR ISSN 2675-6218}

O Quadro 11 se refere à variável " $A$ minha empresa tem sistema de CRM"; mostra um pvalor de 0,323 para a hipótese $\mathrm{H} 0$, um $\mathrm{p}$-valor de 0,117 para a hipótese $\mathrm{H} 1$, e um $\mathrm{p}$-valor de 0,253 para a hipótese $\mathrm{H} 2$, sugerindo que as hipóteses $\mathrm{H} 0, \mathrm{H} 1$ e H2 não devem ser rejeitadas. Ou seja, quando segmentadas por gênero, faixa etária e tempo de atuação na empresa, sugere-se que não há diferença significativa entre as respostas dos gestores.

Sobre o assunto CRM (gerenciamento do relacionamento com o cliente), a maioria $(59,8 \%)$ afirmou não utilizar desse sistema; apenas $26,5 \%$ afirmaram o utilizar, o que indica que esse sistema, apesar de pouco utilizado, poderia ser de grande vantagem para se ter um melhor controle sobre o relacionamento com os clientes.

Tratando-se do gênero, as mulheres discordaram com 57,4\%; e entre os homens o índice é de $64,7 \%$. Quanto à faixa etária, a predominância de discordância foi maior entre os gestores entre 31 e 40 anos (74,2\%); e em relação ao tempo de serviço na empresa, a maior predominância foi no intervalo de 6 a 10 anos, onde 80,8\% também discordou.

Interessante apontar que na questão sobre programa de fidelidade e relacionamento quase $60 \%$ afirmavam que a empresa tem essa prática (Quadro 8), no entanto, quanto ao uso efetivo de um sistema de gerenciamento de relacionamento com cliente, o índice ficou abaixo dos $30 \%$, isso indica que o CRM, que tem como proposta gerar bons relacionamentos com os clientes e utilizar informações de seus dados pessoais, tem sido muito pouco utilizado (REIS et al., 2016).

Quadro 11 - A minha empresa tem sistema de CRM

\begin{tabular}{|c|c|c|c|c|c|c|c|c|c|c|}
\hline & Gênero & \multicolumn{3}{|c|}{ Faixa etária } & \multicolumn{3}{c|}{ Tempo de atuação na empresa } & \\
\hline Escala & Fem. & Masc. & Até 30 & $\mathbf{3 1 / 4 0}$ & $\mathbf{4 0}+$ & Até 1 & $\mathbf{2} / \mathbf{5}$ & $\mathbf{6} / \mathbf{1 0}$ & $\mathbf{1 0}+$ & Total \\
\hline Concordo & $30,9 \%$ & $17,6 \%$ & $33,3 \%$ & $19,4 \%$ & $24,1 \%$ & $39,1 \%$ & $27,6 \%$ & $19,2 \%$ & $20,8 \%$ & $26,5 \%$ \\
\hline Indiferente & $11,8 \%$ & $17,6 \%$ & $21,4 \%$ & $6,5 \%$ & $10,3 \%$ & $13,0 \%$ & $24,1 \%$ & $0,0 \%$ & $16,7 \%$ & $13,7 \%$ \\
\hline Discordo & $57,4 \%$ & $64,7 \%$ & $45,2 \%$ & $74,2 \%$ & $65,5 \%$ & $47,8 \%$ & $48,3 \%$ & $80,8 \%$ & $62,5 \%$ & $59,8 \%$ \\
\hline Total & $100,0 \%$ & $100,0 \%$ & $100,0 \%$ & $100,0 \%$ & $100,0 \%$ & $100,0 \%$ & $100,0 \%$ & $100,0 \%$ & $100,0 \%$ & $100,0 \%$ \\
\hline
\end{tabular}

Fonte: Dados da pesquisa (2020)

O Quadro 12 se refere à variável "A minha empresa utiliza as redes sociais para conquistar novos clientes"; mostra um p-valor de 0,000 para a hipótese $\mathrm{H} 0$, um p-valor de 0,008 para a hipótese $\mathrm{H} 1$, e um $\mathrm{p}$-valor de 0,381 para a hipótese $\mathrm{H} 2$. Isto posto, devem ser rejeitadas as hipóteses $\mathrm{H} 0$ e H1, e a hipótese $\mathrm{H} 2$ não deve ser rejeitada.

Em relação à utilização de redes sociais para conquistar novos consumidores, observa-se que a maioria $(64,7 \%)$ concordou com a afirmação. O público feminino, em sua maioria $(77,9 \%)$, concordou sobre o uso das redes sociais; já o público masculino teve um índice menor de concordância, com 38,2\%. Em relação à faixa etária, a maior predominância de concordância foi na faixa etária de até 30 anos de idade $(78,6 \%)$. Já em relação ao tempo de serviço, a predominância foi entre os respondentes com até um ano de empresa, com $73,9 \%$ de concordância.

Diante dos dados obtidos, observa-se que a utilização da rede social como ferramenta de relacionamento está sendo bastante utilizada pelas empresas, nas diversas mídias sociais 


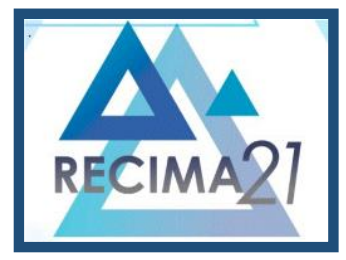

\section{RECIMA21 - REVISTA CIENTÍFICA MULTIDISCIPLINAR ISSN 2675-6218}

conhecidas, como o Facebook, Instagram, Linkedin, Youtube, o que ajuda a estreitar contato junto ao cliente de forma que é possível compreender sua necessidade e preferências por meio da interação das estratégias utilizadas (GABRIEL, 2010; CHIUSOLI et al., 2020).

Importante destacar que o marketing de relacionamento só tem a beneficiar ambas as partes, empresa e clientes, pois muitos consumidores adquirem produtos e serviços de empresas que os tratam e atendem bem, onde se sentem importantes e queridos pelos funcionários. Também é importante criar um ambiente onde os clientes possam perceber que estão fazendo um bom negócio com a empresa, oferecendo, por exemplo descontos, brindes, sorteios, entre outras formas de conquistar e chamar a atenção dos mesmos, principalmente por meio das redes sociais, muito importantes para as estratégias de fidelização e para o marketing de relacionamento (SILVA et al., 2016).

Quadro 12 - A minha empresa utiliza as redes sociais para conquistar novos clientes

\begin{tabular}{|c|c|c|c|c|c|c|c|c|c|c|}
\hline & Gênero & \multicolumn{3}{|c|}{ Faixa etária } & \multicolumn{3}{c|}{ Tempo de atuação na empresa } & \\
\hline Escala & Fem. & Masc. & Até 30 & $\mathbf{3 1 / 4 0}$ & $\mathbf{4 0}+$ & Até 1 & $\mathbf{2} / \mathbf{5}$ & $\mathbf{6} / \mathbf{1 0}$ & $\mathbf{1 0}+$ & Total \\
\hline Concordo & $77,9 \%$ & $38,2 \%$ & $78,6 \%$ & $67,7 \%$ & $41,4 \%$ & $73,9 \%$ & $72,4 \%$ & $65,4 \%$ & $45,8 \%$ & $64,7 \%$ \\
\hline Indiferente & $17,6 \%$ & $38,2 \%$ & $14,3 \%$ & $29,0 \%$ & $34,5 \%$ & $17,4 \%$ & $27,6 \%$ & $19,2 \%$ & $33,3 \%$ & $24,5 \%$ \\
\hline Discordo & $4,4 \%$ & $23,5 \%$ & $7,1 \%$ & $3,2 \%$ & $24,1 \%$ & $8,7 \%$ & $0,0 \%$ & $15,4 \%$ & $20,8 \%$ & $10,8 \%$ \\
\hline Total & $100,0 \%$ & $100,0 \%$ & $100,0 \%$ & $100,0 \%$ & $100,0 \%$ & $100,0 \%$ & $100,0 \%$ & $100,0 \%$ & $100,0 \%$ & $100,0 \%$ \\
\hline
\end{tabular}

Por fim, o Quadro 13 resume os destaques dos resultados do teste Qui-Quadrado, considerando as hipóteses $\mathrm{H} 0, \mathrm{H} 1$ e H2, quando se deve rejeitar ou não ao nível de significância de $1 \%(p \leq 0,01)$ e $5 \%(p \leq 0,05)$.

Quadro 13 - Resumo do teste estatístico não paramétrico: Qui Quadrado

\begin{tabular}{|c|c|c|c|c|c|c|}
\hline & P-valor & $\begin{array}{c}\text { Teste hipótese } \\
\text { Gênero }\end{array}$ & P-valor & $\begin{array}{l}\text { Teste hipótese } \\
\text { Faixa etária }\end{array}$ & P-valor & $\begin{array}{l}\text { Teste hipótese } \\
\text { Tempo serviço }\end{array}$ \\
\hline Quadro 1 & $x x x x x$ & $x x x x x$ & $0,000^{*}$ & Rejeitar $\mathrm{H} 1$ & $0,000^{*}$ & Rejeitar H2 \\
\hline Quadro 2 & $0,000^{*}$ & Rejeitar $\mathrm{HO}$ & Xxxxx & $x x x x x$ & $0,000^{*}$ & Rejeitar H2 \\
\hline Quadro 3 & $0,000^{*}$ & Rejeitar $\mathrm{H} 0$ & $0,000^{*}$ & Rejeitar H1 & $x x x x x$ & $x x x x x$ \\
\hline Quadro 4 & $0,003^{*}$ & Rejeitar $\mathrm{H} 0$ & $0,001^{*}$ & Rejeitar H1 & 0,128 & Não rejeitar H2 \\
\hline Quadro 5 & $0,001^{*}$ & $\operatorname{ar~} \mathrm{HO}$ & $0,000^{*}$ & & $0,042^{\star \star}$ & Rejeitar H2 \\
\hline Quadro 6 & $0,015^{\star \star}$ & Rejeitar $\mathrm{HO}$ & 0,584 & Não rejeitar H1 & 0,470 & Não rejeitar H2 \\
\hline Quadro 7 & $0,019^{\star \star}$ & Rejeitar $\mathrm{H} 0$ & $0,001^{*}$ & Rejeitar H1 & $0,000^{*}$ & Rejeitar H2 \\
\hline Quadro 8 & $0,000^{*}$ & Rejeitar $\mathrm{H} 0$ & $0,009^{*}$ & Rejeitar $\mathrm{H} 1$ & 0,159 & Não rejeitar H2 \\
\hline Quadro 9 & 0,072 & Não rejeitar HO & $0,004^{*}$ & Rejeitar H1 & $0,010^{*}$ & Rejeitar H2 \\
\hline Quadro 10 & 0,223 & Rejeitar H0 & 0,720 & Não rejeitar H1 & $0,027^{* *}$ & Rejeitar H2 \\
\hline Quadro 11 & 0,323 & Não rejeitar H0 & 0,117 & Não rejeitar H1 & 0,253 & Não rejeitar H2 \\
\hline Quadro 12 & $0,000^{*}$ & Rejeitar H0 & $0,008^{*}$ & Rejeitar H1 & 0,381 & Não rejeitar H2 \\
\hline
\end{tabular}

Fonte: autores (2020) - significativo a $1 \%(p \leq 0,01)^{\star}$ e $5 \%(p \leq 0,05)^{\star *}$

\section{GERAÇÃO E RECOMENDAÇÕES}




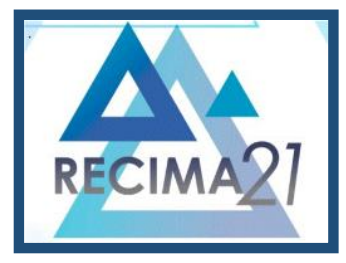

\section{RECIMA21 - REVISTA CIENTÍFICA MULTIDISCIPLINAR ISSN 2675-6218}

O objetivo do trabalho foi atingido, uma vez que buscava analisar as estratégias empresariais quanto à importância e ao uso da fidelização de clientes.

Constatou-se, por meio da investigação realizada junto aos gestores, que a maioria das empresas $(78,4 \%)$ entende sim a importância de fidelizar seus clientes; por outro lado, apenas 33,3\% afirmaram disponibilizar em suas empresas treinamento aos funcionários, para que possam atender os clientes da melhor maneira possível; e apenas $26,5 \%$ afirmaram contar com um sistema de CRM (Gerenciamento do Relacionamento com o Cliente).

Considerando ainda os dados obtidos, 59,8\% concordam que a empresa tem programas de fidelidade e relacionamento aos clientes; e 65,7\% afirmam que a empresa possui estratégias de fidelização de clientes. Esses achados sugerem que, muitas vezes, as empresas não estão totalmente preparadas para implantar estratégias de fidelização, por falta de informação e ferramentas que as auxiliem. Outro dado importante é que a maioria, 91,2\% das empresas entrevistadas, afirmam que estão constantemente buscando conhecer e ter um bom relacionamento com seus clientes, isso demonstra que os gestores estão cada vez mais interessados em melhorar seu relacionamento e proximidade com seus clientes, o que é um ponto positivo para fidelizar essa clientela.

Outro fato interessante é que $64,7 \%$ dos entrevistados dizem utilizar as redes sociais para conquistar novos consumidores, o que nos dias atuais pode ser utilizado como uma vantagem competitiva, pois o marketing vem evoluindo, e sua nova forma digital consegue ter um maior alcance e levar a imagem da empresa a um grande número de pessoas.

Um ponto que pode ser destacado como necessidade de melhorias seria, além da adoção de sistemas de CRM, um maior controle efetivo de quais são os clientes fiéis, tendo em vista que $40,2 \%$ têm controle efetivo de quais são os clientes fiéis, muito embora, apenas $9,8 \%$ citam que a empresa perdeu clientes que antes eram fiéis.

Como já visto, o processo de fidelização de clientes torna-se importante para as organizações, tendo em vista que as estratégias utilizadas pelas empresas, para este fim, oferecem muitas vantagens para conquistar seus clientes e torná-los fiéis à empresa, levando a mesma a obter maior lucro, crescimento e permanecer sempre em uma ótima posição no mercado em relação aos seus concorrentes. Portanto, neste trabalho, buscou-se analisar a respeito da gestão empresarial, por meio da compreensão de como se dá o marketing de relacionamento e a fidelização de clientes, bem como qual é a opinião e atitude desse grupo de gestores e empresários investigados.

Torna-se evidente que a aplicação das estratégias de fidelização de clientes nas empresas favorece muito o crescimento, consequentemente, o lucro dela, e também traz melhorias no relacionamento entre a organização e os seus clientes. Com essa premissa, os clientes se tornarão mais próximos da empresa, não somente pelo fato de comprar da empresa, como também de fazer o marketing "boca a boca" para as pessoas com quem convivem, aumentando a credibilidade da organização e levando novos consumidores. 


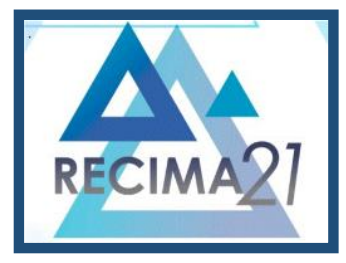

\section{RECIMA21 - REVISTA CIENTÍFICA MULTIDISCIPLINAR ISSN 2675-6218}

Como contribuição da pesquisa, a mesma forneceu informações sobre quais pontos devem ser mais observados pelas empresas para que seus clientes se tornem fiéis, e possibilitou que os empresários, gestores e gerentes pudessem refletir sobre o tema enquanto respondiam ao questionário, uma boa oportunidade para que essas empresas corrigissem ou ampliassem suas estratégias quanto à fidelização de clientes.

As principais limitações que ocorreram na pesquisa foram em obter conhecimento detalhado sobre cada programa e estratégias que estas empresas adotam em seu dia a dia, isso seria um ótimo caminho para uma nova pesquisa desenvolvida por futuros pesquisadores, que poderiam seguir essa ideia de uma maneira mais próxima dos empresários, conseguindo, assim, melhor avaliar e identificar quais pontos podem ser melhorados na empresa. Da mesma forma, a análise fica restrita à amostra de gestores investigados dado a realidade local, não devendo ser generalizados os resultados.

\section{REFERÊNCIAS}

AGUIAR, R. M.; ANJOS, M. A. D. A importância de um bom atendimento ao cliente em um posto de combustível: um estudo de caso no Posto Vila Nova em Monte Carmelo-MG. Revista GeTeC, v. 6, n. $11,2017$.

AUGUSTO, M. N.; ALMEIDA JÚNIOR, O. Marketing de relacionamento: a gestão do relacionamento e suas ferramentas para fidelização de clientes. Revista de Educação, Gestão e Sociedade: Revista Da Faculdade Eça de Queirós, v. 5, p. 1-17, 2015.

CHIUSOLI, C. L. et al. Comportamento dos universitários de instituição pública e privada em relação ao uso das redes sociais: um comparativo. Revista Eletrônica do Alto Vale do Itajaí, v. 9, n. 14, p. 055-068, 2020.

GABRIEL, M. Marketing na era digital. São Paulo: Novatec, 2010.

GIL, A. C. Como elaborar projetos de pesquisa. 6. ed. São Paulo: Atlas, 2017.

GONÇALVES, E. P.; MACHADO, M. B. E.; MARQUES, R. Marketing de relacionamento para fidelizar clientes. Gestão Contemporânea, v. 2, n. 1, 2020.

HOCHMAN, B. et al. Desenhos de pesquisa. Acta Cirúrgica Brasileira, v. 20, p. 2-9, 2005.

HOOLEY, G. J.; SAUNDERS, J. A.; PIERCY, N. F. Estratégia de marketing e posicionamento competitivo. São Paulo: Prentice Hall, 2001.

KNECHTEL, M. R. Metodologia da pesquisa em educação: uma abordagem teórico-prática dialogada. Curitiba: Intersaberes, 2014.

KONDO, E. K. et al. Marketing de relacionamento e estratégias de fidelização de clientes pessoas físicas. Administração: Ensino e Pesquisa, v. 10, n. 3, p. 129-146, 2009.

MATOS, F. O. A.; MOREIRA, R. N. Marketing de relacionamento da loja Use Miaow para fidelização de clientes. Revista de Administração da UNI7, v. 3, n. 1, p. 119-143, 2019.

MATTAR, F. N. Pesquisa de Marketing: Metodologia, planejamento, execução e análise. 7. ed. Rio de Janeiro: Elsevier, 2014. 


\section{RECIMA21 - REVISTA CIENTÍFICA MULTIDISCIPLINAR ISSN 2675-6218}

ESTRATÉGIA DE FIDELIZAC̄̃o COMO PRÁTICA EMPRESARIAL PARA CONQUISTA DE CLIENTES Cláudio Luiz Chiusoli, Dyesli Rita de Oliveira de Souza, Elis Regina Cardoso Lecenko, Isabela Wolski Camargo

MOUTELLA, C. Fidelização de clientes como diferencial competitivo. São Paulo: Portal, 2004.

PANOSSO, G. H.; FROEMMING, L. M. S. Marketing de Relacionamento e sua importância no processo de fidelizar clientes. Salão do Conhecimento, v. 1, n. 1, 2015.

PAULA, L. D. S.; SOUZA, A. C. B. Fidelização de clientes e marketing de relacionamento. Episteme Transversalis, v. 7, n. 1, 2017.

PEREIRA, L. Z.; LEITE, M. M. Fidelização de Clientes como Ferramenta Estratégica: uma Pesquisa de Campo realizada com Clientes de Mercantis localizados na cidade de Brejo SantoCE. Revista de Psicologia, v. 12, n. 42, p. 797-819, 2018.

REIS, A. C. B. C.; IACOVELO, M. T.; ALMEIDA, L. B. B.; COSTA FILHO, B. A. Marketing de relacionamento: agregando valor ao negócio com big data. Revista Brasileira de Marketing, $v$. 15, n. 4, p. 512-523, 2016.

SANTOS, N. D. B.; DIÓGENES, C. Liderança feminina: um estudo pragmático das dificuldades de mulheres em cargos de liderança. Revista RENEFARA, v. 14, n. 2, p. 91-102, 2019.

SCUSSEL, F. B. C.; MARTINIÈRE PETROL, M.; SEMPREBON, E.; ROCHA, R. A. O que é, a final, marketing de relacionamento? uma proposta de conceito unificador. Revista de Ciências da Administração, v. 19, n. 48, p. 9-23, 2017.

SIEGEL, S.; CASTELLAN JUNIOR, N. J. Estatística Não Paramétrica para as Ciências do Comportamento. São Paulo: Artmed-Bookman, 2017.

SILVA, D. F.; SILVA, L. F. M.; ALMEIDA MIRANDA, M. D.; LOPES, V. P.; BARTOLAZZI, V. T. Promoção de vendas: uma ferramenta estratégica para a fidelização de clientes em tempos de crise. Revista Interdisciplinar Pensamento Científico, v. 2, n. 1, 2016.

SOUZA JUNIOR, W.; SARFATI, G. Adoção de programa de fidelidade através de aplicativo móvel: análise do caso Supermercados Meu Econômico através do método de Basket Analysis. Revista Brasileira de Marketing, v. 19, n. 2, p. 287-308, 2020.

UNES, B. V. J.; et al. Fatores relevantes para a fidelização de clientes no setor bancário. Gestão \& Produção, v. 26, n. 2, 2019.

VIEIRA, H. C.; CASTRO, A. E.; JÚNIOR, V. F. S. O uso de questionários via e-mail em pesquisas acadêmicas sob a ótica dos respondentes. XIII SEMEAD Seminários em Administração, 2010. 